\title{
Probing the nuclear import signal and nuclear transport molecular determinants of PRV ICP22
}

\author{
Mingsheng Cai ${ }^{1,2}$, Si Jiang 1,2, Zhancheng Zeng ${ }^{1}$, Xiaowei Li ${ }^{1}$, Chuncong Mo', Yanjia Yang ${ }^{1}$, Chunke Chen', \\ Peiping Xie ${ }^{1}$, Yun Bian ${ }^{1}$, Jinlin Wang ${ }^{1}$, Jinlu Huang ${ }^{3}$, Daixiong Chen ${ }^{1,2}$, Tao Peng $^{2}$ and Meili Li ${ }^{1,2^{*}}$
}

\begin{abstract}
Background: Herpes simplex virus 1 (HSV-1) ICP22 is a multifunctional protein and important for HSV-1 replication. Pseudorabies virus (PRV) ICP22 (P-ICP22) is a homologue of HSV-1 ICP22 and is reported to be able to selectively modify the transcription of different kinetic classes of PRV genes, however, the subcellular localization, localization signal and molecular determinants for its transport to execute this function is less well understood.

Results: In this study, by utilizing live cells fluorescent microscopy, P-ICP22 fused to enhanced yellow fluorescent protein (EYFP) gene was transient expressed in live cells and shown to exhibit a predominantly nucleus localization in the absence of other viral proteins. By transfection of a series of P-ICP22 deletion mutants fused to EYFP, a bona fide nuclear localization signal (NLS) and its key amino acids (aa) of P-ICP22 was, for the first time, determined and mapped to aa 41-60 (PASTPTPPKRGRYVVEHPEY) and aa 49-50 (KR), respectively. Besides, the P-ICP22 was demonstrated to be targeted to the nucleus via Ran-, importin a1-, and a7-mediated pathway.
\end{abstract}

Conclusions: Our findings reported herein disclose the NLS and molecular mechanism for nuclear transport of P-ICP22, these results will uncover new avenues for depicting the biological roles of P-ICP22 during PRV infection.

Keywords: PRV ICP22, Nuclear transport, Nuclear localization signal (NLS), Importin, Ran-GTP

\section{Background}

Pseudorabies virus (PRV), a member of genus Varicellovirus of the subfamily alphaherpesvirinae, is a pathogen of Aujeszky's disease that can infect most mammals except for the higher-order primates. However, the neurotropic nature of PRV makes it a useful tool of neuronal connections and a useful model organism for the research of herpesvirus molecular pathomechanisms [1]. PRV is reported to be closely related to human pathogens varicella-zoster virus (VZV), herpes simplex virus 1 and 2 (HSV-1 and HSV-2) [2], and the animal herpesvirus bovine herpesvirus type 1 (BHV-1) [3]. To analyze the fundamental mechanisms underlying PRV spreading

\footnotetext{
*Correspondence: meili_2011@hotmail.com

${ }^{1}$ Department of Pathogenic Biology and Immunology, School of Basic Science, Guangzhou Medical University, Guangzhou 511436, People's Republic of China

Full list of author information is available at the end of the article
}

and pathogenesis, it is critical to gain a comprehensive understanding of the roles of each gene and their products during viral replication. In the course of lytic cycle of infection, PRV genes are expressed as other herpesviruses in a sequential cascade manner: immediate-early (IE), early (E) and late (L). PRV ICP22 (P-ICP22), the gene product of $U S 1$, does not express as an IE protein in the PRV life cycle, whereas its homologues HSV-1 ICP22 and VZV ORF63 are demonstrated to act as IE proteins [4], and BHV-1 BICP22 exhibits IE and L transcription kinetics [5]. As important proteins for herpesviruses replication, P-ICP22 homologues play many roles in various aspects during infection, such as BHV-1 BICP22 is documented to act as a transrepressor protein on viral promoters of different kinetic classes [6]. Moreover, HSV-1 ICP22 is implicated in ensuring proper virion morphology [7], inducing the formation of discrete nuclear foci containing cellular chaperone proteins known as VICE 
domains [8], modulating viral and cellular genes expressions or their activity $[9,10]$ and phosphorylated by viral and cellular kinases and nucleotidylylated by casein kinase II $[11,12]$. Besides, VZV ORF63 is also involved in modulating viral and cellular genes expressions [13, 14], inhibiting apoptosis of primary human neurons [15] and the efficient establishment of latency [14]. Recently, a paper reported that P-ICP22 is able to selectively modify the transcription of different kinetic classes of PRV genes, this may probably happen in the nucleus and/or the cytoplasm [16], however, the subcellular localization, transport signal and nucleo-cytoplasmic transport mechanism utilized by P-ICP22 to execute this function is less well understood.

In this work, live cells fluorescence microscopy and coimmunoprecipitation (Co-IP), which are widely applied and developed in our group [17-24], were employed to characterize the exact subcellular localization, localization signal and transport mechanism of P-ICP22. We showed that P-ICP22 localized predominantly to the nucleus in the absence of other viral proteins in transient transfected live cells. By sequence analysis and constructing a series of deletion mutants of P-ICP22 fused to enhanced yellow fluorescent protein (EYFP), the precise nuclear localization signal (NLS) and its key amino acids (aa) of P-ICP22 was identified and mapped to aa 41-60 and aa 49-50, respectively. Besides, the molecular mechanisms of nuclear import, which are crucial for understanding P-ICP22-mediated biological effects in
PRV infection cycle, were characterized to target to the nucleus through a Ran-, importin $\alpha 1$ - and $\alpha 7$-dependent nuclear import pathway.

\section{Results and discussion}

Subcellular localization of P-ICP22 in the transfected live cells

It is common knowledge that verification of subcellular localization is one way to disclose the potential roles of some proteins. In the present study, the fate of P-ICP22 distribution was determined by fluorescence microscopy technique. Plasmid encoding P-ICP22 fused to the $\mathrm{N}$ terminus of EYFP was constructed and transfected into COS-7 cells to detect the subcellular localization of P-ICP22 in live cells in the absence of other viral proteins. As a result, P-ICP22-EYFP exhibited predominantly nuclear localization (Fig. 1), which is similar with the result that in HSV-1-infected cell ICP22 also mainly locates in the nucleus, particularly in the small, dense nuclear bodies early in infection and in the diffuse replicative complexes after the onset of DNA synthesis [25].

Although P-ICP22 was predicted to be localized mainly in the cytoplasm [26], it was substantiated here that it predominantly accumulates in nucleus, it's well known that protein phosphorylation is one of the most normal and essential types of protein modification, and certain aspects of cell process modulation are regulated by protein phosphorylation. Signal transduction, proliferation, differentiation and metabolism are all controlled by the

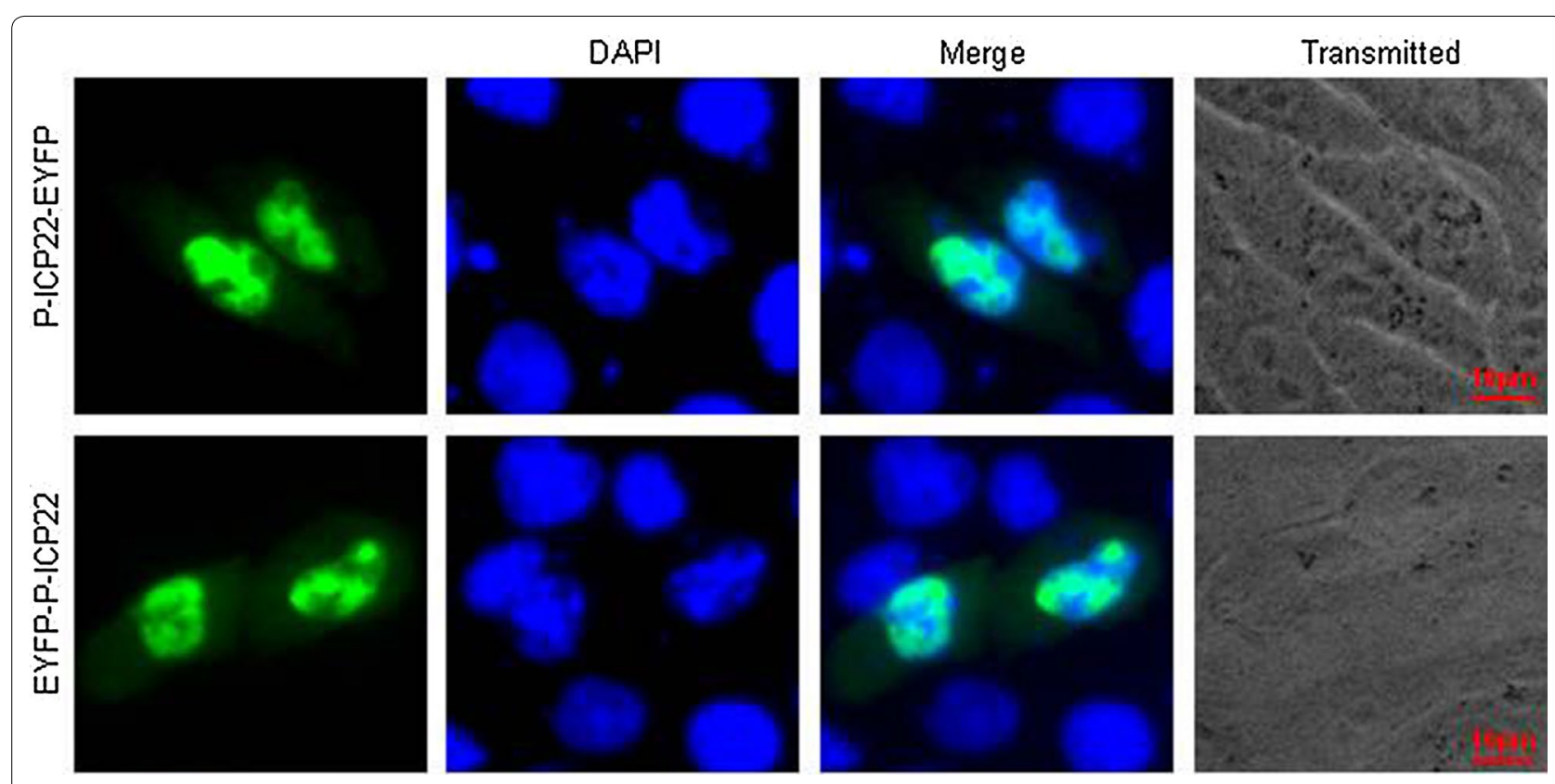

Fig. 1 Subcellular localization of P-ICP22 in transfected living cells. Subcellular distribution of P-ICP22-EYFP and EYFP-P-ICP22 in transfected-COS-7 cells. Cells were stained with DAPI to visualize the nuclei. All scale bars indicate $10 \mathrm{um}$ 
balance of activity of protein kinases and protein phosphatases upon pivotal target proteins. Phosphorylation site prediction revealed there is 22 potential phosphorylation sites in P-ICP22, including 15 serine, 5 threonine and 2 tyrosine residues [26]. Tyrosine phosphorylation is reported to be involved in the replication of several herpesviruses $[27,28]$ and in shifting protein translocation from the cytoplasm to the nucleus during productive virus infection [29]. Phosphorylation of VZV ORF63 is also associated with its subcellular localization and transcriptional regulatory properties [30,31]. Therefore, the subcellular localization differences of P-ICP22 between the predicted result and experiment result may be due to the presence of potential phosphorylation sites especially the tyrosine residues, and P-ICP22 phosphorylation may also play an important role during PRV infection, perhaps in modulating its subcellular localization or other uncharacterized functions, such as transcriptional regulation.

In an attempt to examine whether the location of EYFP influences the localization of P-ICP22 in cells, a plasmid expressing P-ICP22 fused to the $\mathrm{C}$ terminus of EYFP (EYFP-P-ICP22) was constructed, and fluorescence microscopy showed identical subcellular distribution patterns of P-ICP22-EYFP with EYFP-P-ICP22 (Fig. 1). Therefore, subsequent experiments were done using pP-ICP22-EYFP.

\section{Characterization of the NLS and its key aa of P-ICP22}

It is well known that NLSs are mainly composed of basic residues [32]. Sequence analysis using PSORT II predicted that P-ICP22 has a potential NLS in the argininerich region, namely PPKRGRYV at aa 47-54 (contains ${ }^{49} \mathrm{KR}^{50}$ ). In order to determine whether this potential NLS is functional, firstly, two deletion mutants (aa1-180EYFP and aa181-349-EYFP) were constructed within the P-ICP22-EYFP fusion protein (Fig. 2a). Then, these two constructs were tested in COS-7 cells. As shown in Fig. 2b, the fluorescence of aa1-180-EYFP showed absolutely nuclear localization, whereas the fluorescence of 181-349-EYFP showed cytoplasmic localization, suggesting aa 1-180 contains functional NLS. To further determine the functional NLS, plasmids encoding EYFP fused to two different peptides (aa 1-60 and aa 61-180) were constructed (Fig. 2a) and tested in COS-7 cells. As shown in Fig. 2b, fluorescence of aa1-60-EYFP was identical to that of aa1-349-EYFP. In contrast, fluorescence of aa61-180-EYFP showed identical subcellular localization pattern to the negative control EYFP (Fig. 2c), with diffuse fluorescence throughout both the cytoplasm and the nucleoplasm (pan-cellular subcellular localization), suggesting that the region of aa 1-60 contains a functional NLS.

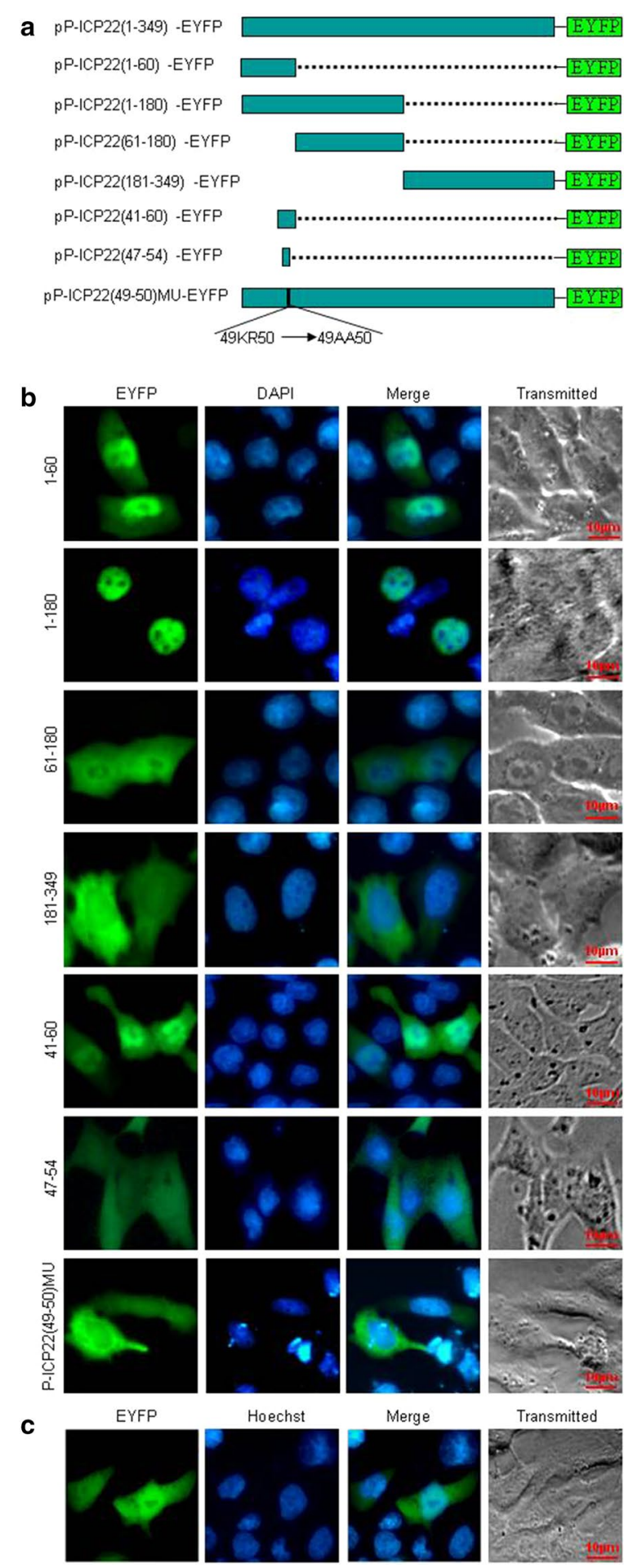

Fig. 2 Subcellular localization of the P-ICP22 deletion mutants. a Schematic representation of wild-type P-ICP22 protein and its $\mathrm{N}$ - and C-terminal deletion mutants fused with EYFP. b Subcellular localization of these P-ICP22 deletion mutants shown in (a). c Subcellular distribution of the negative control EYFP in transfected-COS-7 cells. Cells were stained with DAPI to visualize the nuclei. All scale bars indicate 10 um 
To finally define the minimum region that has the ability to direct EYFP to the nucleus, plasmids encoding EYFP fused to aa 41-60 and aa 47-54 were constructed (Fig. 2a) and tested in COS-7 cells. As shown in Fig. 2b, fluorescence of aa47-54-EYFP was identical to that of EYFP, whereas fluorescence of aa41-60-EYFP showed predominant nuclear localization, suggesting the predicted NLS ( ${ }^{47}$ PPKRGRYV $\left.{ }^{54}\right)$ is not a genuine NLS, and the functional NLS in P-ICP22 is a 20-residue peptide ${ }^{41}$ PASTPTPPKRGRYVVEHPEY ${ }^{60}$, and its key aa may be ${ }^{49} \mathrm{KR}^{50}$.

To further verify this deduction, basic residues within the ${ }^{49} \mathrm{KR}^{50}$ sequences of P-ICP22 was mutated with neutral alanine residues to yield ${ }^{49} \mathrm{AA}^{50}$, and fused with EYFP to create pP-ICP22-49-50mut-EYFP (Fig. 2a). As shown in Fig. 2b, mutation of aa 49-50 within P-ICP22 abrogated the nuclear localization of P-ICP22, showing pancytoplasm subcellular localization pattern, confirming aa 49-50 is the key aa of NLS for the nuclear localization of P-ICP22.

\section{Characterization of the nuclear import mechanisms of P-ICP22}

The Ran protein has been documented to be required for NLS dependent nuclear import, and most transport processes studied to date require the Ran GTPase protein [33]. In order to investigate the nuclear import mechanism of P-ICP22, a DN RanGTP (Ran-Q69L), which lacks the ability in GTP hydrolysis [34], was used to probe whether Ran is required for the nuclear transport of P-ICP22. COS-7 cells were co-transfected with P-ICP22-EYFP and Ran-Q69L-ECFP, and their subcellular localization patterns were observed. As a result, co-transfection of Ran-Q69L significantly blocked the nuclear import of P-ICP22 (Fig. 3a), indicating that $\mathrm{P}-\mathrm{ICP} 22$ protein is a Ran-dependent protein and is transported into the nucleus from the cytoplasm through a classical nuclear transport pathway.

A well-characterized NLS is recognized by members of the importin family of cellular transporters. As documented, the importin $\alpha / \beta$ heterodimer, where importin $\alpha$ recognizes the NLS, and importin $\beta$ promotes the importin $\alpha$-NLS binding by modulating a conformational change in importin $\alpha$ [35]. Then, the importin $\alpha / \beta$-cargo complex is imported to the nucleus and is separated by the Ran-GTP binding with importin $\beta 1$ [36]. In mammals, there are at least six isoforms of karyopherins- $\alpha$, which could be calssified into three different subfamilies on the basis of their sequence similarity: the Rch1 subfamily (importin $\alpha 1 /$ Rch 1 ), the Qip1 subfamily (importin $\alpha 3 /$ Qip1 and importin $\alpha 4 /$ Qip2), and the NPI-1 subfamily (importin $\alpha 5 / \mathrm{NPI}-1$, importin $\alpha 6$, and importin $\alpha 7 /$ NPI-2) $[37,38]$. Besides the importin $\alpha / \beta$ mechanism, it is described that there are at least ten importin $\beta$-dependent nuclear import/ export pathways [39], the NLSs of which could be directly recognized by several importin $\beta$ members, especially the extensively studied importin $\beta 1$ and importin $\beta 2$ (transportin-1) [40]. To pursue the cellular receptor assume P-ICP22 nuclear targeting and further explore the nuclear import pathway of P-ICP22, DN importin $\beta 1(\mathrm{DN} \mathrm{k} \beta 1)$ [41] and DN importin $\alpha 5$ (DN k $\alpha 1$ ) [42], which deficient in binding Ran and importin $\beta[43,44]$, respectively, and nuclear transport inhibitors M9M and Bimax2 that are specific for the transportin-1 [45] or importin $\alpha 1, \alpha 3, \alpha 6$ and $\alpha 7$ [46] pathways, respectively, were also introduced to confirm whether they are required for the nuclear transport of P-ICP22. Compared with the negative control cells that only transfected with DN k $\beta 1, \mathrm{DN} k \alpha 1, \mathrm{M} 9 \mathrm{M}$ or Bimax2 (Fig. 3b), co-transfection of the negative control ECFP (Fig. $4 \mathrm{~b}$ ), DN k $\beta 1, \mathrm{DN} k \alpha 1$ or $\mathrm{M} 9 \mathrm{M}$ did not changed the localization of P-ICP22 (Fig. 4a), however, Bimax2 could obviously impair the nuclear import of P-ICP22 and redistributed it to the cytoplasm, suggesting that P-ICP22 may be transported into the nucleus by at least one of proteins from importin $\alpha 1, \alpha 3, \alpha 6$ or $\alpha 7$, but not importin $\beta 1$, importin $\alpha 5$ or transportin-1.

\section{P-ICP22 binds importin a1 and importin a7}

It is well known that distinct type of cells can express almost all the importins (highly conserved among various types of cells) that involved in the transport of cargos [47, 48]. To further verify the hypothesis mentioned above, Co-IP assays were implemented. HEK293T cells, expressing endogenous importins including importin $\alpha$ [48], were co-transfected with either of the following available plasmid combinations: pCMV9-3 × Flag-importin $\beta 1 /$ pICP22-EYFP, pcDNA-Flag-k $\alpha 1$ (importin $\alpha 5$ )/pICP22EYFP, $\quad$ pFLAG-CMV-transportin-1/pICP22-EYFP, Flag-k $\alpha 2$ (importin $\alpha 1$ )/pICP22-EYFP, Flag-k $\alpha 4$ (importin $\alpha 3$ )/pICP22-EYFP or Flag-k $\alpha 6$ (importin $\alpha 7$ )/pICP22EYFP. $24 \mathrm{~h}$ post transfection, cell lysates were collected and Co-IP was carried out using anti-Flag mAb or mouse IgG. Immunoprecipitated proteins were subjected to western-blot analysis with Flag and YFP antibodies. As results, P-ICP22 was efficiently co-immunoprecipitated with importin $\alpha 1$ (Fig. 5d) and $\alpha 7$ (Fig. 5f), but not importin $\beta 1$ (Fig. 5a), importin $\alpha 5$ (Fig. 4b), transportin-1 (Fig. 5c) or importin $\alpha 3$ (Fig. 5e). As control, no target protein was immunoprecipitated by IgG (Fig. 5), indicating P-ICP22 is associated with importin $\alpha 1$ and $\alpha 7$.

In conclusion, the subcellular localization, localization signal and nuclear transport mechanism of P-ICP22 were identified in this study. P-ICP22 is shown to principally localized to the nucleus. By 


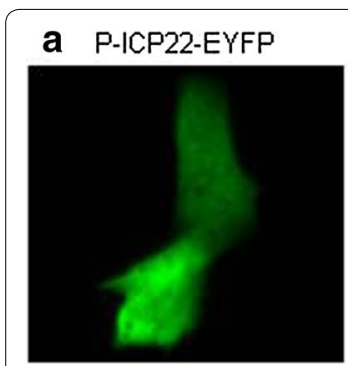

b

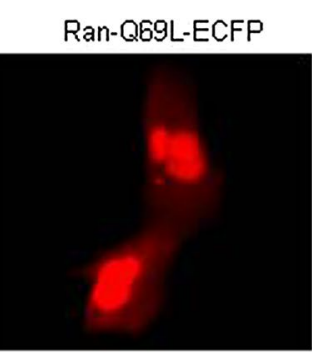

ECFP/RFP
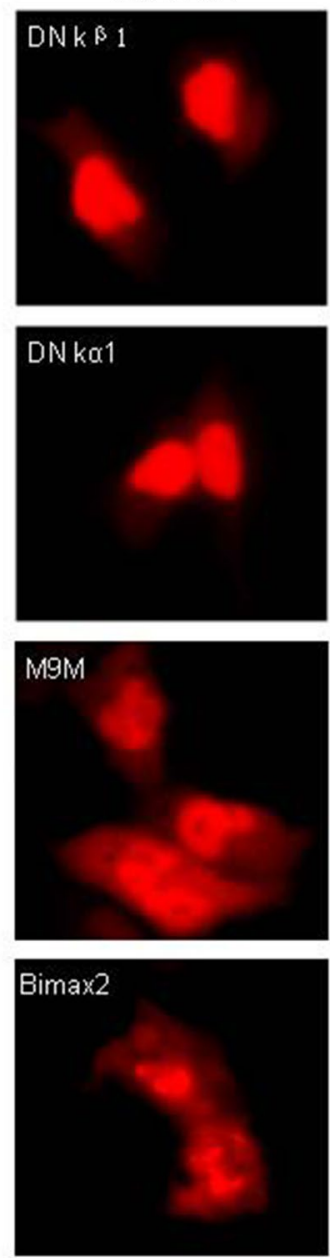

\section{EYFP+ECFP}

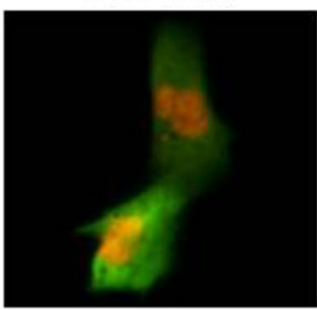

Transmitted
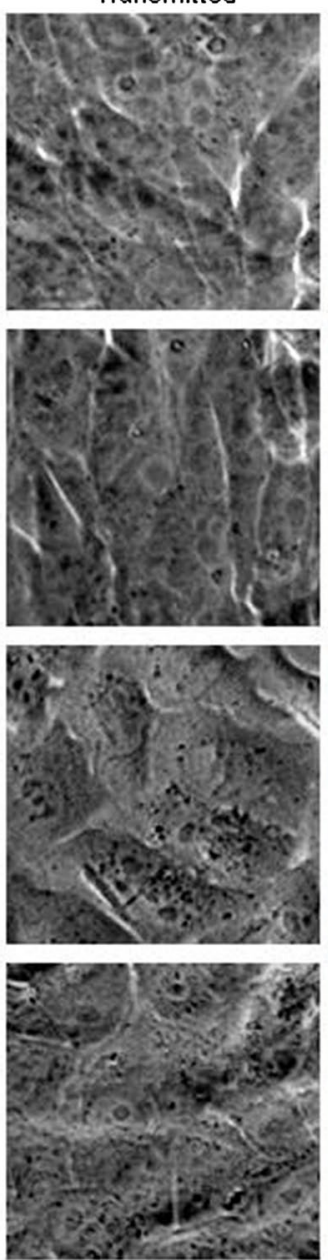
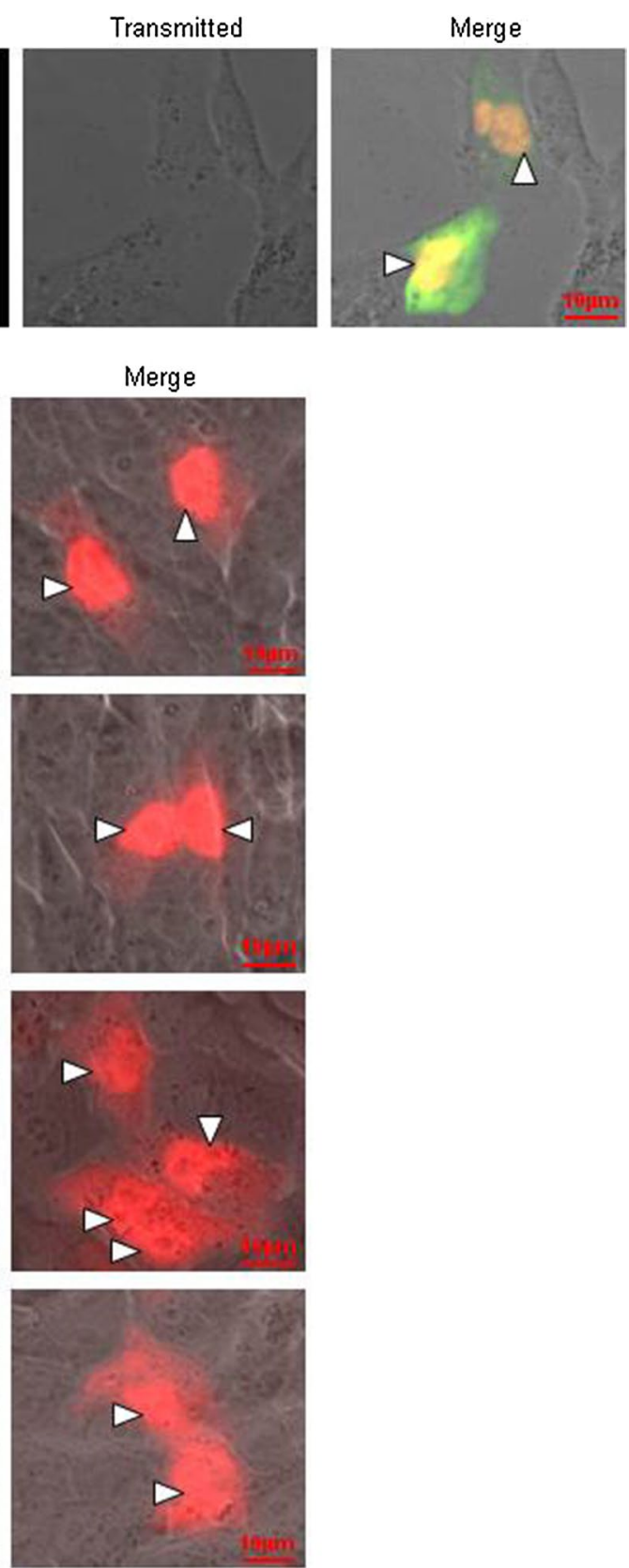

Fig. 3 Ran-dependent nuclear import of P-ICP22. a Fluorescence microscopy of COS-7 cells co-transfected with plasmids pP-ICP22-EYFP and pRanQ69L-ECFP. b Fluorescence microscopy of COS-7 cells only transfected with plasmid encoding DN kB1-ECFP, DN ka1-ECFP, M9M-RFP or Bimax2-RFP. The white arrowhead showed the nuclei in a cell that co-transfected with two plasmids. All scale bars indicate 10 um

constructing a series of deletion mutants fused with EYFP and fluorescence microscopy analysis, we identified an N-terminal arginine-rich functional NLS $\left({ }^{41}\right.$ PASTPTPPKR GRYVVEHPEY $\left.{ }^{60}\right)$ in P-ICP22, and ${ }^{49} \mathrm{KR}^{50}$ is the crucial aa for its nuclear localization. In addition, P-ICP22 was characterized to import into the nucleus via Ran-, importin $\alpha 1$ - and $\alpha 7$ - mediated pathway, which would expand its list of the host targets, and P-ICP22 probably transports into the nucleus via Ran-, importin $\alpha 1$ - and $\alpha 7$ - mediated pathway to selectively modify the transcription of different kinetic classes of PRV genes. Therefore, this study reveals the molecular mechanisms for the nuclear transport of P-ICP22, and will advance the understanding 

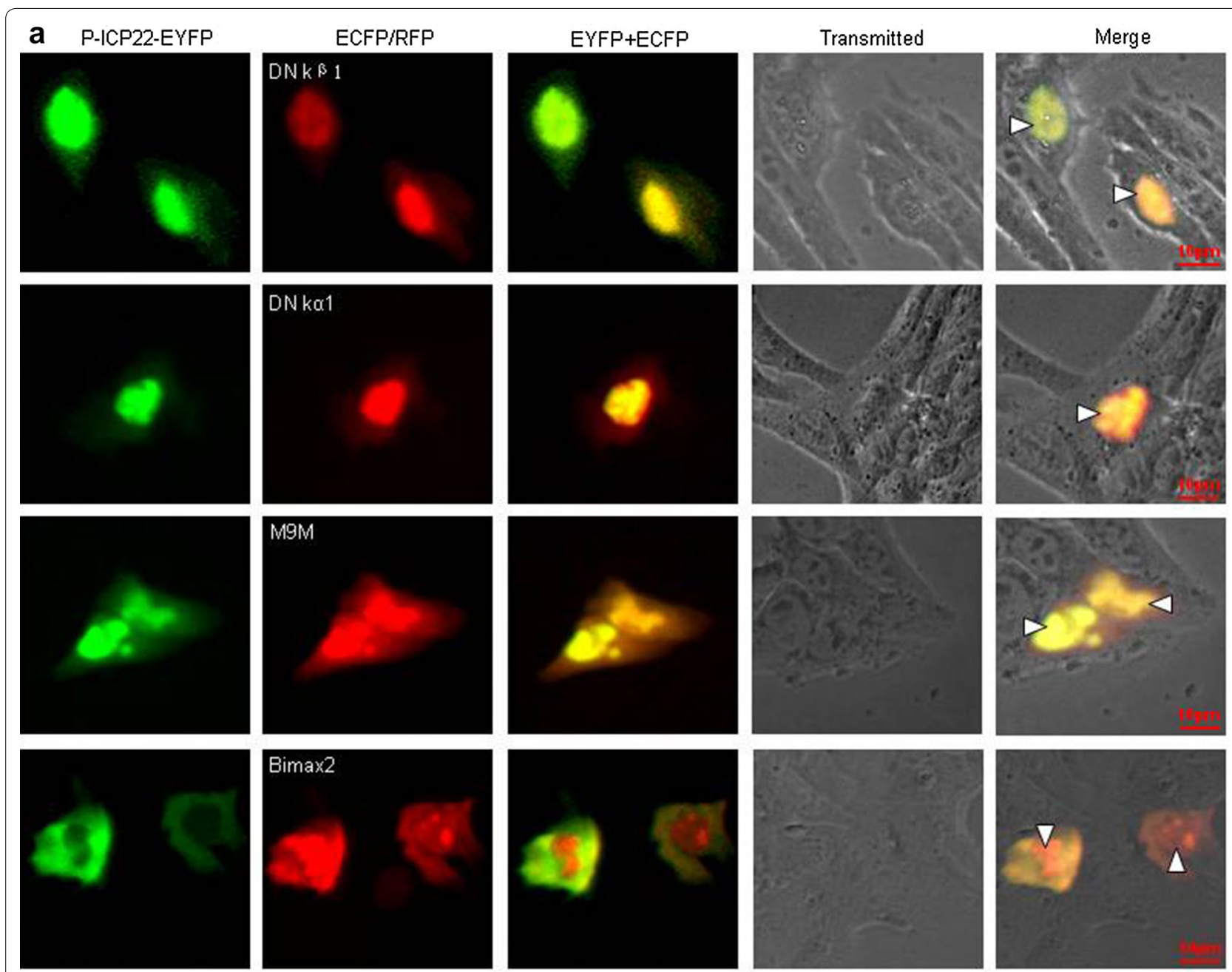

b P-ICP22-EYFP

ECFP
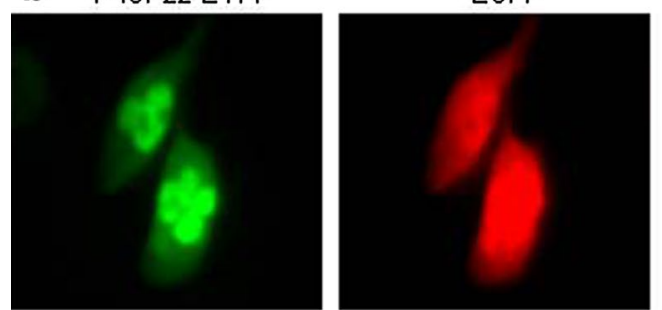

EYFP+ECFP

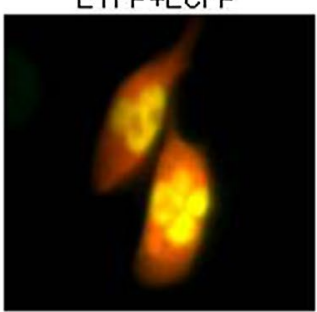

Transmitted

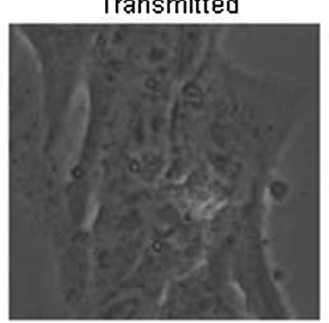

Merge

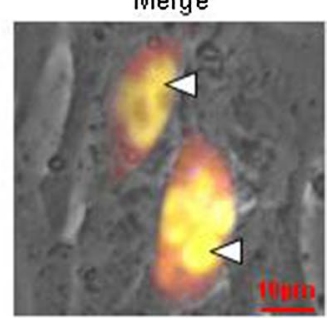

Fig. 4 The nuclear import mechanism of P-ICP22. a Fluorescence microscopy of COS-7 cells co-transfected with plasmid PP-ICP22-EYFP and plasmid encoding DN kß1-ECFP, DN ka1-ECFP, M9M-RFP or Bimax2-RFP, respectively. b Fluorescence microscopy of COS-7 cells co-transfected with PP-ICP22-EYFP and pECFP-N1. The white arrowhead showed the nuclei in a cell that co-transfected with two plasmids. All scale bars indicate 10 um

of P-ICP22-mediated biological functions in PRV replication.

\section{Methods}

\section{Plasmids construction}

All enzymes used for cloning processes were purchased from Takara (Dalian, China) except DNA polymerase KOD FX from TOYOBO and T4 DNA ligase from New
England Biolabs (MA, USA). PRV BAC pBecker2 was a generous gift from Dr. Lynn W. Enquist [49]. The P-ICP22 ORF (composed of 1047 bp) was amplified via PCR from the genomic DNA of PRV Becker strain pBecker2. After the PCR amplified product was validated as the intended product, it was purified using a PCR gel purification kit (Qiagen) according to the manufacturer's instructions. The product was then digested with EcoRI and BamHI 


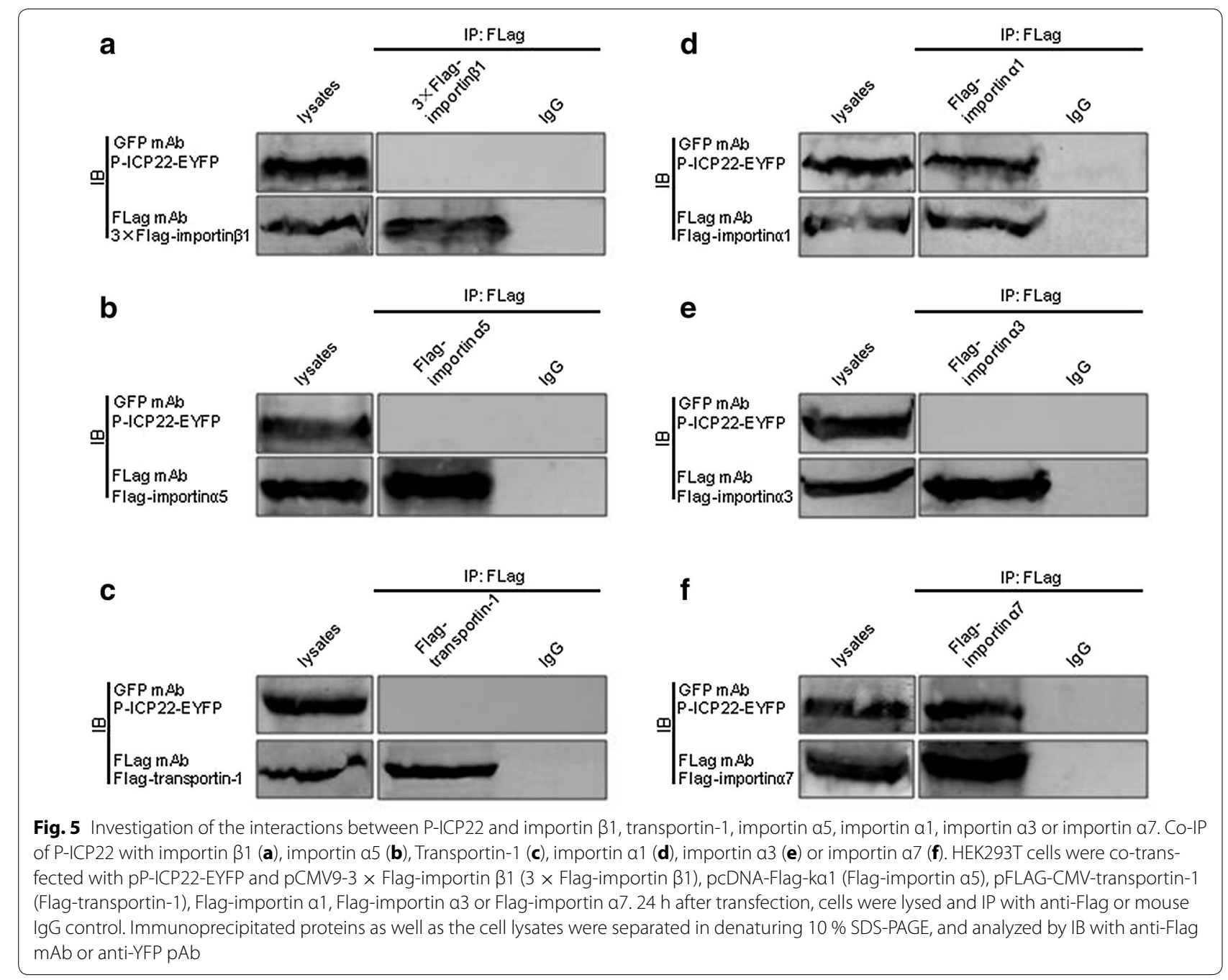

and inserted into the correspondingly digested green fluorescent protein variant mammalian expression vector pEYFP-N1 (Clontech) encoding EYFP at $16{ }^{\circ} \mathrm{C}$ overnight using T4 DNA ligase, to create the recombinant plasmid named pP-ICP22-EYFP, as described previously [3, 26, 50-53]. After mini-scale isolation of plasmid DNA using Qiagen plasmid Mini kits (Qiagen), the presence of the appropriate insert in the obtained plasmid was confirmed by PCR, restriction analysis and sequencing. Subsequently, the P-ICP22 ORF was subcloned into pEYFP-C1 (Clontech) to yield pEYFP-P-ICP22. The series of mutant deletions were generated by PCR-ligation-PCR mutagenesis [54] using appropriate primers and cloned into pEYFP-N1 as described above, all the $\mathrm{N}$ terminal deleted fusion proteins were inserted with an artificial ATG start codon starting at internal positions in P-ICP22 of the fusion constructs. Finally, all constructs were verified by PCR, restriction analysis and sequencing. Dominant negative (DN) mutant RanGTP [55], DN k $\alpha 1$ [42] and
DN k $\beta 1$ [41] were subcloned into pECFP-N1 (Clontech) to generate pRan-Q69L-ECFP, $\mathrm{pDN}$ k $\alpha 1$-ECFP and pDN k $\beta 1$-ECFP, respectively. RFP-Bimax2 and RFP-M9M were generous gifts from Dr. Nobuyuki Nukina [56]. pcDNAFlag-k $\alpha 1$ (importin $\alpha 5$ ), Flag-k $\alpha 6$ (importin $\alpha 7$ ) [57], Flag-k $\alpha 2$ (importin $\alpha 1$ ), Flag-k $\alpha 4$ (importin $\alpha 3$ ) [58] and pCMV9-3 $\times$ Flag-importin $\beta 1$ were the generous gifts from Drs. Yoshihiro Yoneda, Reinhard Depping and Ben Margolis, respectively. The transportin-1 ORF was amplified from pGEX-tev-kapbeta2 [59] and subcloned into pFLAG-CMV-2 (Sigma) to produce pFLAG-CMV-transportin-1. All the primers used in this study are available upon request.

\section{Transfection and fluorescence microscopy}

Transfection and fluorescence microscopy assays were fulfilled as shown in our previous studies [23, 53]. Briefly, to express the proteins in vitro, COS-7 cells were plated onto six-well plates (Corning) in DMEM with $10 \%$ FBS 
at a density of $\sim 2.5 \times 10^{5}$ cells per well overnight to 60-80\% confluency before transfection. The next day, monolayer of COS-7 cells were transfected with 1.0$1.5 \mu \mathrm{g}$ of indicated plasmid DNA mixed with Thermo Scientific TurboFect Transfection Reagent following the manufacturer's instructions. The transfection efficiency ( $60 \%$ ) was determined by EYFP. 24 h post transfection, cells were washed with fresh growth medium and subjected to fluorescence microscopy with a Zeiss Axiovert $200 \mathrm{M}$ microscope (Germany). In the same experiment, each transfection was performed for at least three times. Data shown were from one representative experiment. All the photomicrographs were taken under a magnification of $400 \times$. Each photomicrograph represents an enormous majority of the cells with similar subcellular localization. Both fluorescent images of EYFP and ECFP fusion proteins were presented in pseudocolor, green and red, respectively, and the merged images were shown to prove the colocalization and appeared in yellow signals. All scale bars indicate $10 \mathrm{um}$. Images were processed by Adobe Photoshop.

\section{Co-IP and western-blot}

Co-IP and western-blot were manipulated as described previously [23, 53]. Briefly, HEK293T cells $\left(\sim 2.5 \times 10^{6}\right)$ were co-transfected with $5 \mu \mathrm{g}$ of each of the indicated expression plasmids bearing EYFP or Flag tag. Transfected cells were harvested $24 \mathrm{~h}$ post transfection and lysed on ice with $1 \mathrm{~mL}$ of lysis buffer. For each IP, a $0.5 \mathrm{~mL}$ aliquot of lysate was incubated with $0.5 \mu \mathrm{g}$ of the anti-Flag monoclonal antibody (mAb) or nonspecific control mouse antibody (IgG) and $30 \mu \mathrm{L}$ of 1:1 slurry of Protein A/G PLUS-Agarose (Santa Cruz Biotechnology) for at least $4 \mathrm{~h}$ or overnight at $4{ }^{\circ} \mathrm{C}$. The Sepharose beads were washed three times with $1 \mathrm{~mL}$ of lysis buffer containing $500 \mathrm{mM} \mathrm{NaCl}$. Subsequently, the immunoprecipitated proteins, as well as the cell lysates, were subjected to immunoblotting (IB) analysis with anti-Flag $\mathrm{mAb}$ (Sigma) and anti-YFP polyclonal antibody (pAb) (Santa Cruz Biotechnology). All Co-IP were repeated at least two times, and similar data were obtained.

\begin{abstract}
Abbreviations
PRV: pseudorabies virus; P-ICP22: PRV ICP22; IE: immediate-early; E: early; L: late; VZV: varicella-Zoster virus; HSV-1: herpes simplex virus 1; BHV-1: bovine herpesvirus type 1; EYFP: enhanced yellow fluorescent protein; NLS: nuclear localization signal; DN: dominant negative; ECFP: enhanced cyan fluorescent protein; Co-IP: co-immunoprecipitation; mAb: monoclonal antibody; pAb: polyclonal antibody; IB: immunoblotting.
\end{abstract}

\section{Authors' contributions}

Conceived and designed the experiments: MSC and MLL. Performed the experiments and analyzed the data: MSC, CCM, ZCZ, SJ, XWL, YJY, CKC, PPX, YB, JLW, JLH, DXC, TP and MLL. Wrote the paper: MSC and MLL. All authors contributed to and have approved the final manuscript.

\section{Author details}

${ }^{1}$ Department of Pathogenic Biology and Immunology, School of Basic Science, Guangzhou Medical University, Guangzhou 511436, People's Republic of China. ${ }^{2}$ Guangzhou Hoffmann Institute of Immunology, School of Basic Science, Guangzhou Medical University, Guangzhou 511436, People's Republic of China. ${ }^{3}$ Guangdong Haid Group Co., Ltd., Guangzhou 511400, People's Republic of China.

\section{Acknowledgements}

We thank Drs. Lynn W. Enquist, Yoshinari Yasuda, Haitao Guo, Nobuyuki Nukina, Yoshihiro Yoneda, Ben Margolis, Christopher F. Basler, Donna D. Zhang, Christoph Kaether and Reinhard Depping for the generous gifts of pBecker2, pGEXRan-Q69L, DN ka1, DN kß1, RFP-M9M/RFP-Bimax2, pcDNA-Flag-ka1 (importin a5), pCMV9-3 × FLAG-importin $\beta 1$, Flag-ka6 (importin a7), Flag-ka2 (importin a1) and Flag-ka4 (importin a3), respectively. We also thank Dr. Chunfu Zheng (Institutes of Biology and Medical Sciences, Soochow University) for the technical assistance and supply of COS-7 and HEK293T cells.

\section{Competing interests}

The authors declare that they have no competing interests.

\section{Funding}

This work was supported by grants from the National Natural Science Foundation of China (31400150 and 31200120); the Natural Science Foundation of Guangdong Province (2015A030313473 and S2013040016596); the Foundation for Distinguished Young Talents in Higher Education of Guangdong, China (2013LYM_0096); the Pearl River S\&T Nova Program of Guangzhou (2013J2200018); the Science and Technology Program of Guangzhou, China (201504291022514); the Scientific Research Projects in Colleges and universities of Guangzhou (1201430024); the Scientific Research Foundation for the Ph.D., Guangzhou Medical University (2014C02); the Medical Scientific Research Foundation of Guangdong Province, China (B2012165); the Training Program for Outstanding Young Teachers in Universities of Guangdong Province (YQ2015132); the Thousand Hundred Ten Projects of Guangzhou Medical University, Guangdong; the Science and Technology Plan Projects of Guangdong Province, China (2013B031800022); and the Students' extracurricular scientific and technological activities in Guangzhou Medical University (2015A003, 2015A008, 2015A019 and 2015B020).

Received: 4 August 2015 Accepted: 10 January 2016

Published online: 25 January 2016

\section{References}

1. Pomeranz LE, Reynolds AE, Hengartner CJ. Molecular biology of pseudorabies virus: impact on neurovirology and veterinary medicine. Microbiol Mol Biol Rev. 2005;69:462-500.

2. Kramer T, Greco TM, Enquist LW, Cristea IM. Proteomic characterization of pseudorabies virus extracellular virions. J Virol. 2011;85:6427-41.

3. Li ML, Zhao ZY, Cui W, Mo CC, Wang JL, Cai MS. Molecular cloning and characterization of the pseudorabies virus UL31 gene. Genet Mol Res. 2014;13:1832-47.

4. Zhang G, Leader DP. The structure of the pseudorabies virus genome at the end of the inverted repeat sequences proximal to the junction with the short unique region. J Gen Virol. 1990;71 (Pt 10):2433-41.

5. Schwyzer M, Wirth UV, Vogt B, Fraefel C. BICP22 of bovine herpesvirus 1 is encoded by a spliced $1.7 \mathrm{~kb}$ RNA which exhibits immediate early and late transcription kinetics. J Gen Virol. 1994;75(Pt 7):1703-11.

6. Koppel R, Vogt B, Schwyzer M. Immediate-early protein BICP22 of bovine herpesvirus 1 trans-represses viral promoters of different kinetic classes and is itself regulated by BICPO at transcriptional and posttranscriptional levels. Arch Virol. 1997;142:2447-64.

7. Orlando JS, Balliet JW, Kushnir AS, Astor TL, Kosz-Vnenchak M, Rice SA, Knipe DM, Schaffer PA. ICP22 is required for wild-type composition and infectivity of herpes simplex virus type 1 virions. J Virol. 2006;80:9381-90.

8. Bastian TW, Livingston CM, Weller SK, Rice SA. Herpes simplex virus type 1 immediate-early protein ICP22 is required for VICE domain formation during productive viral infection. J Virol. 2010;84:2384-94. 
9. Advani SJ, Weichselbaum RR, Roizman B. Herpes simplex virus 1 activates cdc2 to recruit topoisomerase II alpha for post-DNA synthesis expression of late genes. Proc Natl Acad Sci USA. 2003;100:4825-30.

10. Bowman JJ, Orlando JS, Davido DJ, Kushnir AS, Schaffer PA. Transient expression of herpes simplex virus type 1 ICP22 represses viral promoter activity and complements the replication of an ICP22 null virus. J Virol. 2009;83:8733-43.

11. Rice SA, Long MC, Lam V, Spencer CA. RNA polymerase II is aberrantly phosphorylated and localized to viral replication compartments following herpes simplex virus infection. J Virol. 1994;68:988-1001.

12. Kalamvoki M, Roizman B. The histone acetyltransferase CLOCK is an essential component of the herpes simplex virus 1 transcriptome that includes TFIID, ICP4, ICP27, and ICP22. J Virol. 2011;85:9472-7.

13. Jones JO, Arvin AM. Viral and cellular gene transcription in fibroblasts infected with small plaque mutants of varicella-zoster virus. Antiviral Res. 2005;68:56-65.

14. Ambagala AP, Cohen J. Varicella-Zoster virus IE63, a major viral latency protein, is required to inhibit the alpha interferon-induced antiviral response. J Virol. 2007;81:7844-51.

15. Hood C, Cunningham AL, Slobedman B, Arvin AM, Sommer MH, Kinchington PR, Abendroth A. Varicella-zoster virus ORF63 inhibits apoptosis of primary human neurons. J Virol. 2006;80:1025-31.

16. Takacs IF, Tombacz D, Berta B, Prazsak I, Poka N, Boldogkoi Z. The ICP22 protein selectively modifies the transcription of different kinetic classes of pseudorabies virus genes. BMC Mol Biol. 2013;14:2.

17. Li ML, Wang S, Cai MS, Zheng CF. Identification of nuclear and nucleolar localization signals of pseudorabies virus (PRV) early protein UL54 reveals that its nuclear targeting is required for efficient production of PRV. J Virol. 2011;85:10239-51.

18. Li ML, Wang S, Cai MS, Guo H, Zheng CF. Characterization of molecular determinants for nucleocytoplasmic shuttling of PRV UL54. Virology. 2011;417:385-93.

19. Li ML, Wang L, Ren XM, Zheng CF. Host cell targets of tegument protein VP22 of herpes simplex virus 1. Arch Virol. 2011;156:1079-84.

20. Li ML, Jiang S, Wang JL, Mo CC, Zeng ZC, Yang YL, Chen CK, Li XW, Cui W, Huang $J$, et al. Characterization of the nuclear import and export signals of pseudorabies virus UL31. Arch Virol. 2015;160:2591-4.

21. Li ML, Cui W, Mo CC, Wang JL, Zhao ZY, Cai MS. Cloning, expression, purification, antiserum preparation and its characteristics of the truncated UL6 protein of herpes simplex virus 1. Mol Biol Rep. 2014;41:5997-6002.

22. Cai MS, Li ML, Wang KZ, Wang S, Lu Q, Yan JH, Mossman KL, Lin RT, Zheng CF. The herpes simplex virus 1-encoded envelope glycoprotein B activates NF-kappaB through the Toll-like receptor 2 and MyD88/TRAF6dependent signaling pathway. PLoS One. 2013;8:e54586.

23. Cai MS, Wang S, Long J, Zheng CF. Probing of the nuclear import and export signals and subcellular transport mechanism of varicella-zoster virus tegument protein open reading frame 10. Med Microbiol Immunol. 2012;201:103-11.

24. Li ML, Jiang S, Mo CC, Zeng ZC, Li XW, Chen CK, Yang YJ, Wang JL, Huang $J$, Chen DX, Peng T, Cai MS. Identification of molecular determinants for the nuclear import of pseudorabies virus UL31. Arch Biochem Biophys. 2015;587:12-7.

25. Jahedi S, Markovitz NS, Filatov F, Roizman B. Colocalization of the herpes simplex virus 1 UL4 protein with infected cell protein 22 in small, dense nuclear structures formed prior to onset of DNA synthesis. J Virol. 1999;73:5132-8.

26. Li ML, Chen JH, Zhao ZY, Zhang KJ, Li Z, Li J, Mai JY, Zhu XM, Cai MS. Molecular cloning and characterization of the pseudorabies virus US1 gene. Genet Mol Res. 2013;12:85-98.

27. Geiss BJ, Tavis JE, Metzger LM, Leib DA, Morrison LA. Temporal regulation of herpes simplex virus type 2 VP22 expression and phosphorylation. J Virol. 2001;75:10721-9.

28. Ren X, Harms JS, Splitter GA. Tyrosine phosphorylation of bovine herpesvirus 1 tegument protein VP22 correlates with the incorporation of VP22 into virions. J Virol. 2001;75:9010-7.

29. Pomeranz LE, Blaho JA. Modified VP22 localizes to the cell nucleus during synchronized herpes simplex virus type 1 infection. J Virol. 1999;73:6769-81.

30. Habran L, Bontems S, Di Valentin E, Sadzot-Delvaux C, Piette J. Varicellazoster virus IE63 protein phosphorylation by roscovitine-sensitive cyclin-dependent kinases modulates its cellular localization and activity. J Biol Chem. 2005;280:29135-43.

31. Mueller NH, Walters MS, Marcus RA, Graf LL, Prenni J, Gilden D, Silverstein SJ, Cohrs RJ. Identification of phosphorylated residues on varicella-zoster virus immediate-early protein ORF63. J Gen Virol. 2010;91:1133-7.

32. Emmott E, Hiscox JA. Nucleolar targeting: the hub of the matter. EMBO Rep. 2009;10:231-8.

33. Moore MS, Blobel G. The GTP-binding protein Ran/TC4 is required for protein import into the nucleus. Nature. 1993;365:661-3.

34. Palacios I, Weis K, Klebe C, Mattaj IW, Dingwall C. RAN/TC4 mutants identify a common requirement for snRNP and protein import into the nucleus. J Cell Biol. 1996;133:485-94.

35. Kobe B. Autoinhibition by an internal nuclear localization signal revealed by the crystal structure of mammalian importin alpha. Nat Struct Biol. 1999;6:388-97.

36. Gorlich D, Kutay U. Transport between the cell nucleus and the cytoplasm. Annu Rev Cell Dev Biol. 1999;15:607-60.

37. Goldfarb DS, Corbett AH, Mason DA, Harreman MT, Adam SA. Importin alpha: a multipurpose nuclear-transport receptor. Trends Cell Biol. 2004;14:505-14

38. Ushijima R, Sakaguchi N, Kano A, Maruyama A, Miyamoto Y, Sekimoto T, Yoneda Y, Ogino K, Tachibana T. Extracellular signal-dependent nuclear import of STAT3 is mediated by various importin alphas. Biochem Biophys Res Commun. 2005;330:880-6.

39. Sorokin AV, Kim ER, Ovchinnikov LP. Nucleocytoplasmic transport of proteins. Biochemistry (Mosc). 2007;72:1439-57.

40. Harel A, Forbes DJ. Importin beta: conducting a much larger cellular symphony. Mol Cell. 2004;16:319-30.

41. Guo H, Mao R, Block TM, Guo JT. Production and function of the cytoplasmic deproteinized relaxed circular DNA of hepadnaviruses. J Virol. 2010;84:387-96

42. Reid SP, Valmas C, Martinez O, Sanchez FM, Basler CF. Ebola virus VP24 proteins inhibit the interaction of NPI-1 subfamily karyopherin alpha proteins with activated STAT1. J Virol. 2007;81:13469-77.

43. Kutay U, Izaurralde E, Bischoff FR, Mattaj IW, Gorlich D. Dominant-negative mutants of importin-beta block multiple pathways of import and export through the nuclear pore complex. EMBO J. 1997;16:1153-63.

44. Chi NC, Adam EJ, Adam SA. Different binding domains for Ran-GTP and RanGDP/RanBP1 on nuclear import factor p97. J Biol Chem. 1997;272:6818-22.

45. Cansizoglu AE, Lee BJ, Zhang ZC, Fontoura BM, Chook YM. Structurebased design of a pathway-specific nuclear import inhibitor. Nat Struct Mol Biol. 2007;14:452-4.

46. Kosugi S, Hasebe M, Entani T, Takayama S, Tomita M, Yanagawa H. Design of peptide inhibitors for the importin alpha/beta nuclear import pathway by activity-based profiling. Chem Biol. 2008;15:940-9.

47. Miyamoto Y, Saiwaki T, Yamashita J, Yasuda Y, Kotera I, Shibata S, Shigeta M, Hiraoka Y, Haraguchi T, Yoneda Y. Cellular stresses induce the nuclear accumulation of importin alpha and cause a conventional nuclear import block. J Cell Biol. 2004;165:617-23.

48. Shin I, Rotty J, Wu FY, Arteaga CL. Phosphorylation of p27Kip1 at Thr-157 interferes with its association with importin alpha during $\mathrm{G} 1$ and prevents nuclear re-entry. J Biol Chem. 2005;280:6055-63.

49. Smith GA, Enquist LW. A self-recombining bacterial artificial chromosome and its application for analysis of herpesvirus pathogenesis. Proc Natl Acad Sci USA. 2000;97:4873-8.

50. Cai MS, Wang BY, Cui W, Zhao ZY, Chen JH, Wen XM, Li Z, Li ML. Molecular characterization of the pseudorabies virus UL2 gene. Genet Mol Res. 2013;12:4147-61.

51. Li ML, Cui W, Zhao ZY, Mo CC, Wang JL, Chen YL, Cai MS. Molecular cloning and characterization of pseudorabies virus EPO gene. Indian J Biochem Biophys. 2014;51:100-14.

52. Cai MS, Wang JL, Mo CC, Zeng ZC, Yang YJ, Chen CK, Li XW, Cui W, Li ML. Preparation and identification of an antiserum against recombinant UL31 protein of pseudorabies virus. Acta Virol. 2015;59:295-9.

53. Li ML, Li Z, Li WT, Wang BY, Ma CQ, Chen JH, Cai MS. Preparation and characterization of an antiserum against truncated UL54 protein of pseudorabies virus. Acta Virol. 2012;56:315-22.

54. Ali SA, Steinkasserer A. PCR-ligation-PCR mutagenesis: a protocol for creating gene fusions and mutations. Biotechniques. 1995;18:746-50.

55. Isegawa Y, Miyamoto Y, Yasuda Y, Semi K, Tsujimura K, Fukunaga R, Ohshima A, Horiguchi Y, Yoneda Y, Sugimoto N. Characterization of the 
human herpesvirus 6 U69 gene product and identification of its nuclear localization signal. J Virol. 2008;82:710-8.

56. Kino Y, Washizu C, Aquilanti E, Okuno M, Kurosawa M, Yamada M, Doi H, Nukina N. Intracellular localization and splicing regulation of FUS/TLS are variably affected by amyotrophic lateral sclerosis-linked mutations. Nucleic Acids Res. 2011;39:2781-98.

57. Mizuguchi C, Moriyama T, Yoneda Y. Generation and characterization of a monoclonal antibody against importin alpha7/NPI-2. Hybridoma (Larchmt). 2011;30:307-9.
58. Depping R, Steinhoff A, Schindler SG, Friedrich B, Fagerlund R, Metzen E, Hartmann E, Kohler M. Nuclear translocation of hypoxia-inducible factors (HIFs): involvement of the classical importin alpha/beta pathway. Biochim Biophys Acta. 2008; 1783:394-404.

59. Chook YM, Blobel G. Structure of the nuclear transport complex karyopherin-beta2-Ran x GppNHp. Nature. 1999;399:230-7.
Submit your next manuscript to BioMed Central and we will help you at every step:

- We accept pre-submission inquiries

- Our selector tool helps you to find the most relevant journal

- We provide round the clock customer support

- Convenient online submission

- Thorough peer review

- Inclusion in PubMed and all major indexing services

- Maximum visibility for your research

Submit your manuscript at www.biomedcentral.com/submit
() Biomed Central 